A - Research concept and design

B - Collection and/or assembly of data

$\mathrm{C}$ - Data analysis and interpretation

D - Writing the article

E - Critical revision of the article

F - Final approval of article

\section{Diastasis recti abdominis - what may cause it in postpartum women?}

\author{
Dominika Gruszczyńska*A-F (D), Aneta Dąbek ${ }^{A-C, E}$ (D), \\ Witold Rekowskic
}

Józef Piłsudski University of Physical Education in Warsaw, Poland

*Correspondence: Dominika Gruszczyńska; Józef Piłsudski University of Physical Education in Warsaw, Poland; email: dm.gruszczynska@gmail.com

\begin{abstract}
Introduction: Diastasis recti abdominis (DRA) is both a structural and a functional disorder. It is believed that the main cause of DRA is the extensive stretching of the abdominal wall resulting from pregnancy; yet the condition is also found in men and in children. There are several, seemingly mutually exclusive, DRA risk factors, such as the pathological abdominal muscle tension and chronic exercise deficits. The aim of the study was to determine the factors affecting the size of DRA in postpartum women.

Material and methods: The study involved 239 postpartum women. The study was conducted with the use of an online survey. The subjects completed the DRA test, the Beighton test and International Physical Activity Questionnaire.

Results: The analysis found DRA in majority of studied women (60.7\%). The relationship between the BMI index and DRA was statistically significant $(\mathrm{p}=0.01)$. The relationship between surgeries in the abdominal cavity and the DRA was statistically significant, too $(p=0.05)$. We showed that DRA correlates with other pelvic dysfunctions $(p=0.03)$.

Conclusions: The most significant risk factors for diastasis recti abdominis in postpartum women are abnormal BMI and surgeries to the abdominal cavity. Diastasis recti abdominis correlates with other dysfunctions, such as: spinal pain, urinary incontinence, peristaltic disorders, sexual disorders, abdominal hernia, groin hernia, lowering of the lesser pelvis organs. Further studies into DRA risk factors under close supervision of a physiotherapist are necessary.
\end{abstract}

Keywords: abdominal muscles, postpartum period, pregnancy, risk factors, rectus abdominis

\section{Introduction}

The problem of rectus abdominis diastasis affects $33 \%$ to $75 \%$ women who had had a child [1-3]. According to Katy Bowman, DRA is such a prevalent postpartum condition that it is widely believed to be inevitable, to be related with hormonal changes and to the extensive stretching of the abdominal wall. Surprisingly, the main causes of DRA are usually bad movement habits (too little exercise, too monotonous or badly performed exercise) repeated for the whole life [4].

Even though DRA is defined as increased distance between the two muscle bellies of the rectus abdominis, the condition does not only affect the abdominal walls it has significant consequences for the whole body [5]. The most common dysfunctions that accompany DRA 
are: lumbo-pelvic pain [6-8], urinary and fecal incontinence, lowering of lesser pelvis organs [9], sexual disorders [10], and peristaltic disorders [11].

There is extensive literature on the diastasis recti abdominis, yet only a limited number of scientific articles on DRA risk factors [11-15]. Most of the literature focuses on the therapy of DRA patients, and overlooks how important physioprophylactics and causal treatment are. Even the best tailored therapy or surgical treatment $[16,17]$ will not bring lasting effects if the primary source of the problem remains unknown.

The main aim of the study was to assess the relationships between DRA risk factors described in the literature and the prevalence of diastasis rectiabdominis in postpartum women. These risk factors were listed basing on latest literature review. An additional aim of the study was to assess the correlation between DRA prevalence and DRA-accompanying dysfunctions.

\section{Material and methods}

We obtained the consent of the Senate Science Committee to conduct the study (consent number SKE-0115/20). The study involved 241 women aged 19 to 61 years who had given birth to a minimum of one child. The detailed characteristics of the group are presented below (Table 1).

The criteria for subject inclusion were the following: having given birth of a minimum of one child, age between 19 to 49 years, informed consent to participate in the study, no serious diseases such as hypertension or diabetes. Two females were excluded from the group because of the age criterion. 239 women were included in the detailed analysis.

Due to the pandemics of Covid-19 we used a detailed online questionnaire for the study. The questionnaire was posted on young mum social media groups and websites of antenatal classes. The questionnaire was

Tab. 1. Study population characteristics

\begin{tabular}{lccc}
\hline & Mean & $\begin{array}{c}\text { Standard } \\
\text { deviation }\end{array}$ & R min-max \\
\hline Age (years) & 32.75 & 5.76 & $19-61$ \\
Height $(\mathrm{cm})$ & 165.63 & 8.53 & $150-183$ \\
Body mass $(\mathrm{kg})$ & 64.96 & 12.28 & $43-112$ \\
BMI $\left(\mathrm{kg} / \mathrm{m}^{2}\right)$ & 24.05 & 8.99 & $15.41-39.68$ \\
Waist size $(\mathrm{cm})$ & 79.27 & 11.31 & $50-120$ \\
WHR* & 0.81 & 0.07 & $0.59-1.02$ \\
\hline
\end{tabular}

*Waist-to-hip ratio. anonymous and filling it out was voluntary. The questions concerned, inter alia, education, type of work, the course of pregnancy and delivery, everyday habits, surgeries to the abdominal cavity. Additionally, the subjects completed the test for diastasis recti abdominis [11], the Beighton test that assesses joint hypermobility [18] and the International Physical Activity Questionnaire IPAQ - short form [19].

The subjects did the DRA test on their own, basing on the attached illustrations and descriptions. The starting position was lying on the back, with the hip, knees and ankles bent. During the test at rest, the subjects placed one hand under their head, and the other - the dominant hand - palpated the linea alba from the xiphoid process to the pubic symphysis. The DRA assessment in tension was done with the head lifted, on three levels: on the level of the umbilicus, $4.5 \mathrm{~cm}$ above the umbilicus and $4.5 \mathrm{~cm}$ below the umbilicus. The DRA test was positive if the subject could place a minimum of two fingers between the muscle bellies of rectus abdominis [11].

The Beighton test consists of 5 simple actions. To make the test easier to conduct at home, all 5 actions were presented in pictures. The maximum Beighton test score is 9 , yet a score of 4 or higher denotes joint hypermobility [18].

We used the Polish short form of the IPAQ for the study. It consists of 7 questions. The questions concern physical activity of everyday life, work and relax. The total score for the questionnaire allowed us to qualify the subjects into one of three categories for physical activity: poor (lower than 600), moderate (600 to 1500 or 600 to 3000) and high (over 1500 or 3000 MET-min/ week) [19].

\section{Statistical analysis}

We used the SPSS Statistics 20 programme to analyze the variables. The basic method for analysis of contingency tables was the analysis of percentage profiles. We used the Pearson's chi-squared independence test and the measure of association, the Cramer's V. Statistical significance was set at $\mathrm{p}=0.05$.

\section{Results}

On the basis of the DRA test we found that most subjects had diastasis recti abdominis both in rest and in tension (Figure 1). The rectus abdominis self-test at rest revealed DRA in 158 women (66\%), while 83 women (34\%) did not self-diagnose with DRA. The self-test in tension revealed DRA in 147 women $(61 \%)$ and did not reveal DRA in 94 women (39\%). Differences in selftest results in rest and in tension result from the fact that 


\section{DRA in study population}

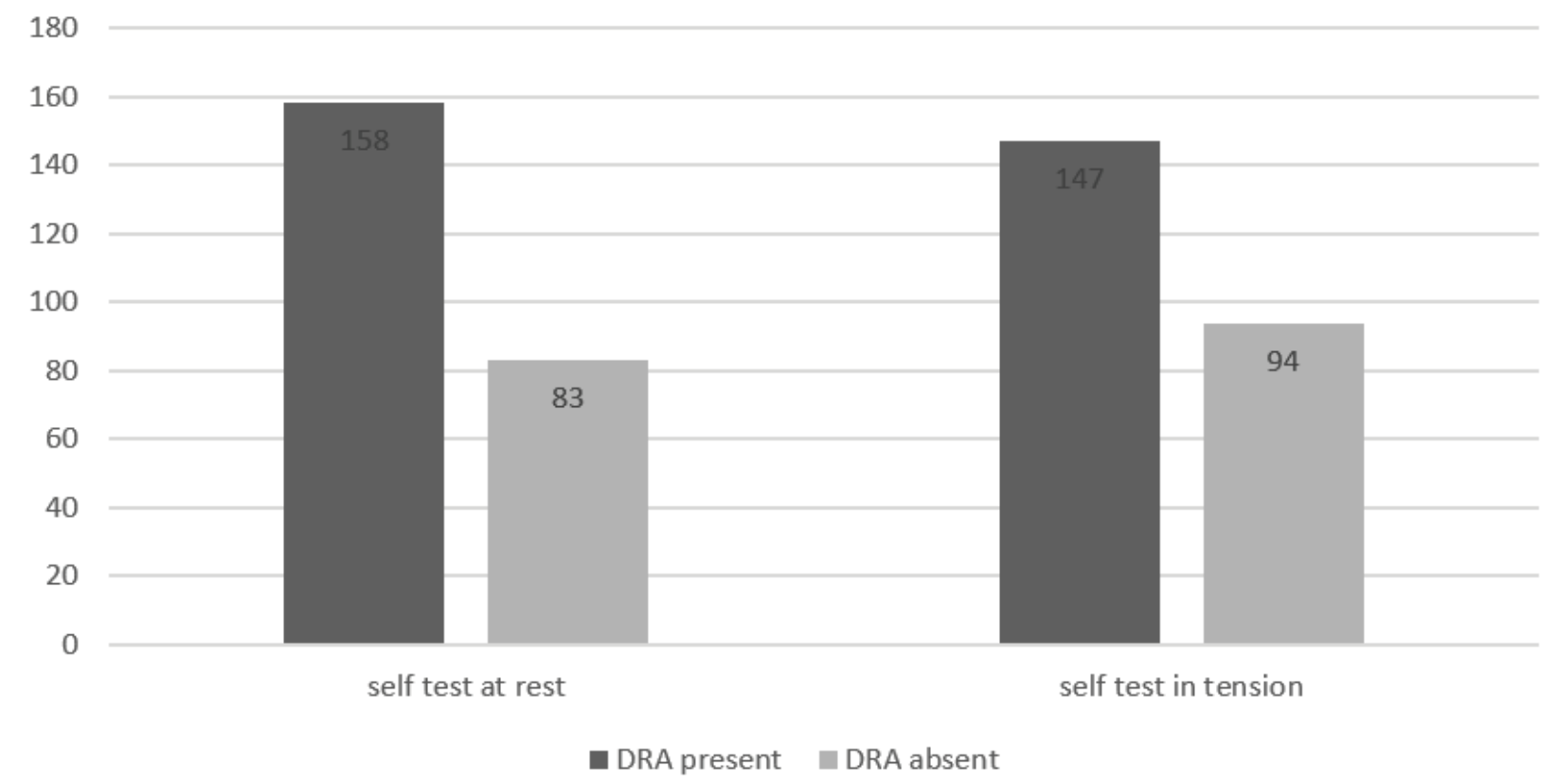

Fig. 1. DRA in study population

tensing the rectus abdominis brings the ventri closer to one another [11].

We analyzed the relationship between age and DRA and the correlation was not statistically significant $(\mathrm{p}=0.91)$. However, we found that DRA prevalence tended to grow with subject's age (Table 2). Relationship between education and DRA was not statistically significant $(\mathrm{p}=0.15)$. The relationship between waist size and DRA prevalence was not statistically significant $(\mathrm{p}=0.28)$, yet basing on the percentage profile analysis we found that DRA prevalence tended be higher in subjects with greater waist size (Table 2). Beighton test result analysis did not reveal any correlation between joint hypermobility and DRA prevalence $(\mathrm{p}=0.96)$ (Table 2). Similarly, DRA did not correlate with the level of physical activity $(\mathrm{p}=1)($ Table 2$)$.

Relationship between BMI and DRA was statistically significant $(\mathrm{p}=0.01)$. We found that BMI both below and above the norm (normal BMI: $18.5-24.99 \mathrm{~kg} / \mathrm{m}^{2}$ ) was related to DRA (Table 3).

We did not find statistically significant relationship between the number of deliveries and DRA $(p=0.62)$. However, there was a rising tendency in percentages. Women who had given birth to more than one baby had DRA more often (Table 4). The type of birth was not a significant correlation factor for DRA, either $(p=0.07)$. Still, DRA was more prevalent in women who had had caesarean section (Table 4).

Body mass and body length of the newborn were not statistically significant for DRA $(p=0.57$, $\mathrm{p}=0.88$ ). Regular use of shapewear (clothes, underwear, belts) did not have statistically significant relationship with DRA $(p=0.59)$. We only found a tendency in the percentage profiles that suggested that among women who used shapewear there were $6.5 \%$ more women with DRA than among those who did not wear it (Table 4).

The study showed that surgeries to the abdominal cavity correlated with DRA $(p=0.05)$ (Table 5).

We found a statistically significant correlation between DRA and other dysfunctions to the pelvis and spine $(p=0.03)($ Table 6$)$.

\section{Discussion}

Even though it is mainly puerperium women who consult physiotherapists with their DRA, the issue concerns many potentially healthy subjects $[20,21]$. We may even risk a statement that with the rising general awareness on the benefits of physical activity on health, the DRA problem will intensify. This results from the fact that physically active subjects often breathe incorrectly. Apnoea increases the intrabdominal pressure and results in significant overburden of the muscles of the local cylinder, including the abdominal muscles, muscles of the back, and the pelvic floor muscles $[4,11,22,23]$.

Disregarded DRA may lead to further health consequences. The studies conducted so far concluded 
Tab. 2. Age, education, waist size, joint mobility, general level of physical ability, and DRA

\begin{tabular}{|c|c|c|c|}
\hline & \multicolumn{2}{|c|}{ DRA } & \multirow{2}{*}{ Total } \\
\hline & Present (\%) & Absent (\%) & \\
\hline \multicolumn{4}{|l|}{ Age } \\
\hline $19-28$ & $59.3(32)$ & $40.7(22)$ & $54(22.6 \%)$ \\
\hline $29-35$ & $60.0(69)$ & $40(46)$ & $115(48.1 \%)$ \\
\hline $36-49$ & $62.9(44)$ & $37.1(26)$ & $70(29.3 \%)$ \\
\hline $\mathrm{Chi}^{2}=0.21$ & $\varphi=0.03$ & & \\
\hline \multicolumn{4}{|l|}{ Education } \\
\hline Secondary and vocational & $70.7(29)$ & $29.3(12)$ & $41(17.2 \%)$ \\
\hline higher & $58.6(116)$ & $41.4(82)$ & $198(82.8 \%)$ \\
\hline $\mathrm{Chi}^{2}=2.1$ & $\varphi=0.9$ & & \\
\hline \multicolumn{4}{|l|}{ Waist size $(\mathrm{cm})$} \\
\hline$<70$ & $54.1(33)$ & $45.9(28)$ & $61(25.5 \%)$ \\
\hline $71-85$ & $60.3(73)$ & $39.7(48)$ & $121(50.6 \%)$ \\
\hline $86-120$ & $68.4(39)$ & $31.6(18)$ & $57(23.8 \%)$ \\
\hline $\mathrm{Chi}^{2}=2.54$ & $\varphi=0.1$ & & \\
\hline \multicolumn{4}{|l|}{ Joint mobility } \\
\hline normal & $60.8(113)$ & $39.2(73)$ & $186(77.8 \%)$ \\
\hline hypermobility & $60.4(32)$ & $39.6(21)$ & $53(22.2 \%)$ \\
\hline $\mathrm{Chi}^{2}=0.00$ & $\varphi=0.00$ & & \\
\hline \multicolumn{4}{|c|}{ General level of physical activity } \\
\hline poor & $60.5(23)$ & $39.5(15)$ & $38(15.9 \%)$ \\
\hline moderate & $60.8(62)$ & $39.2(40)$ & $102(42.7 \%)$ \\
\hline high & $60.6(60)$ & $39.4(39)$ & $99(41.4 \%)$ \\
\hline $\mathrm{Chi}^{2}=0.00$ & $\varphi=0.00$ & & \\
\hline Total & $145(60.7 \%)$ & $94(39.2 \%)$ & $239(100 \%)$ \\
\hline
\end{tabular}

Tab. 3. BMI and DRA

\begin{tabular}{|c|c|c|c|c|}
\hline \multirow{2}{*}{\multicolumn{2}{|c|}{ BMI }} & \multicolumn{2}{|c|}{ DRA } & \multirow{2}{*}{ Total } \\
\hline & & Present (\%) & Absent (\%) & \\
\hline$<$ normal & & $90(9)$ & $10(1)$ & $10(4.2 \%)$ \\
\hline normal & & $54.9(89)$ & $45.1(73)$ & $162(67.8 \%)$ \\
\hline$>$ normal & & $70.1(47)$ & $29.9(20)$ & $67(28 \%)$ \\
\hline Total & & $145(60.7 \%)$ & $94(39.3 \%)$ & $239(100 \%)$ \\
\hline $\mathrm{Chi}^{2}=8.36$ & $\mathrm{P}=0.01$ & $\varphi=0.19$ & & \\
\hline
\end{tabular}

that DRA coexisted with numerous other dysfunctions, such as: peristaltic disorders $(64.9 \%)$, sexual problems $(57.5 \%)$, urinary incontinence $(69 \%)$, prolapse of the lesser pelvis organs $(61 \%)$ or back pain $(64.5 \%)$. The cause of this relationship may be increased intraabdominal pressure distributed incorrectly onto the remaining structures of the local muscle cylinder [11]. Other authors made similar conclusions. Spitznagle et al. studied a population of uroginecological patients. DRA was present in $52 \%$ of subjects. Women with DRA had higher mean age, had been through more deliveries and had weaker pelvic floor muscles than women without 
Tab. 4. Number of pregnancies, the type of last delivery, newborn body mass, newborn body length, regular use of shapewear, and DRA

\begin{tabular}{|c|c|c|c|c|}
\hline & & \multicolumn{2}{|c|}{ DRA } & \multirow{2}{*}{ Total } \\
\hline & & Present $(\%)$ & Absent $(\%)$ & \\
\hline \multicolumn{5}{|c|}{ Number of pregnancies } \\
\hline One & & $55.9(57)$ & $44.1(45)$ & $102(42.7 \%)$ \\
\hline Two & & $64.8(57)$ & $35.2(31)$ & $88(26.8 \%)$ \\
\hline Three & & $63.2(24)$ & $36.8(14)$ & $38(15.9 \%)$ \\
\hline$>4$ & & $63.6(7)$ & $36.8(4)$ & $11(4.6 \%)$ \\
\hline $\mathrm{Chi}^{2}=1.74$ & $\mathrm{P}=0.62$ & $\varphi=0.09$ & & \\
\hline \multicolumn{5}{|c|}{ Type of last delivery } \\
\hline Vaginal deliy & & $55(66)$ & $45(54)$ & $120(50.2 \%)$ \\
\hline Caesarean se & & $66.4(79)$ & $33.6(40)$ & $119(49.8 \%)$ \\
\hline $\mathrm{Chi}^{2}=3.25$ & $\mathrm{P}=0.07$ & $\varphi=0.12$ & & \\
\hline \multicolumn{5}{|c|}{ Newborn body mass (g) } \\
\hline$<3500$ & & $58.8(67)$ & $41.2(47)$ & $114(47.7 \%)$ \\
\hline$>3501$ & & $62.4(78)$ & $37.6(47)$ & $125(52.3 \%)$ \\
\hline $\mathrm{Chi}^{2}=0.33$ & $\mathrm{P}=0.57$ & $\varphi=-0.04$ & & \\
\hline \multicolumn{5}{|c|}{ Newborn body length (cm) } \\
\hline$<55$ & & $60.2(71)$ & $39.8(47)$ & $18(7.5 \%)$ \\
\hline$>56$ & & $61.2(74)$ & $38.8(47)$ & $221(92.5 \%)$ \\
\hline $\mathrm{Chi}^{2}=0.02$ & $\mathrm{P}=0.88$ & $\varphi=-0.01$ & & \\
\hline \multicolumn{5}{|c|}{ Regular use of shapewear } \\
\hline Yes & & $66.7(12)$ & $33.3(6)$ & $118(49.4 \%)$ \\
\hline No & & $60.2(133)$ & $38.8(88)$ & $121(50.6 \%)$ \\
\hline $\mathrm{Chi}^{2}=0.29$ & $\mathrm{P}=0.59$ & $\varphi=0.04$ & & \\
\hline Total & & $145(60.7 \%)$ & $94(39.3 \%)$ & $239(100 \%)$ \\
\hline
\end{tabular}

Tab. 5. Surgeries to the abdominal cavity and DRA

\begin{tabular}{|c|c|c|c|}
\hline \multirow[b]{2}{*}{ Surgeries to the abdominal cavity } & \multicolumn{2}{|c|}{ DRA } & \multirow{2}{*}{ Total } \\
\hline & Present (\%) & Absent (\%) & \\
\hline Yes & $70(49)$ & $30(21)$ & $70(29.3 \%)$ \\
\hline No & $56.8(96)$ & $43.2(73)$ & $169(70.7 \%)$ \\
\hline Total & $145(60.7 \%)$ & $94(39.3 \%)$ & $239(100 \%)$ \\
\hline $\mathrm{Chi}^{2}=3.61$ & & & \\
\hline
\end{tabular}

DRA. As many as $66 \%$ of DRA patients had a minimum of one pelvic floor dysfunction, such as: stress urinary incontinence, fecal incontinence or prolapse of the lesser pelvis organs [9].

The most common risk factors of DRA discussed in the literature are: obesity, pregnancy, movement deficits, hypermobility, incorrect breathing patterns, incorrect exercising, shapewear $[4,11,25-28]$. In our study, the only statistically significant factors were: surgeries to the abdominal cavity and the BMI index. Other authors made similar conclusions. In their study, Turan et al. found a relationship between DRA and number of pregnancies, and surgeries to the abdominal cavity. They believed that a greater number of pregnancies and repeated surgeries to the abdominal cavity increased the risk of developing DRA [24]. 
Tab. 6. Accompanying dysfunctions and DRA

\begin{tabular}{|c|c|c|c|}
\hline \multirow{2}{*}{ Accompanying dysfunctions } & \multicolumn{2}{|c|}{ DRA } & \multirow{2}{*}{ Total } \\
\hline & Present $(\%)$ & Absent $(\%)$ & \\
\hline Present & 64.2 & 35.8 & $190(79.5 \%)$ \\
\hline Absent & 46.9 & 53.1 & $49(20.5 \%)$ \\
\hline $\mathrm{Chi}^{2}=4.87$ & & & \\
\hline \multicolumn{4}{|l|}{ Dysfunctions } \\
\hline Spinal pain & 64.5 & 35.5 & 152 \\
\hline Urinary incontinence & 69 & 31 & 42 \\
\hline Peristaltic disorders & 64.9 & 35.1 & 57 \\
\hline Sexual disorders & 57.5 & 42.5 & 40 \\
\hline Abdominal hernia & 80.5 & 19.5 & 41 \\
\hline Groin hernia & 50 & 50 & 4 \\
\hline Lowering of the organs of the lesser pelvis & 60.9 & 39.1 & 23 \\
\hline None & 44.7 & 55.3 & 47 \\
\hline Total & $144(60.7 \%)$ & $94(39.3 \%)$ & $239(100 \%)$ \\
\hline
\end{tabular}

A study by Bobowik and Dąbek on 40 women in early postpartum period (1-3 days) found statistically significant correlations between the size of DRA and BMI, WHR, and increase of body mass during pregnancy. The higher the BMI and WHR and body mass increase in pregnancy were, the greater were the diastases recti abdominis in postpartum women. A proprietary six -week therapeutic programme proved to be an efficient method for reducing both the DRA and the BMI [28].

It is difficult to explicitly explain the correlation we found in this study between the DRA and low BMI. This interesting issue necessitates further detailed studies, possibly with the use of a device for measuring body composition.

DRA risk factors, such as age, education, waist size, number of pregnancies or shapewear were not statistically significant in our study, yet we observed certain tendencies. Interestingly, there was no significant relationship between physical activity and DRA, and between hypermobility and DRA.

Sperstad et al. verified over a dozen of factors that may affect DRA. Their tests were conducted at time intervals: 21 st week of pregnancy, 6 weeks postpartum, 6 months postpartum, 12 months postpartum. In their study, age, height, mean pre-pregnancy body mass, pregnancy body mass increase, type of birth, newborn body mass, frequent lifting of the baby or of heavy objects, abdominal muscle training, pelvic floor muscle training, general training 12 months postpartum did not impact DRA. Similarly, joint hypermobility verified with the Beighton test was not related to DRA, either [13].
The study conducted at the women's hospital in Vancouver (Canada) was meant to answer the question on what affected DRA. The study compared two groups of females: females without or with insignificant DRA, and women with moderate or significant DRA. The study found that women without or with insignificant DRA did energetic exercise and regular walking (once or twice a week) during pregnancy much more frequently than the other group. A tendency was found among women who had more than one child to have a greater diastasis recti abdominis, and Candido et al. believed that it was caused by frequent lifting of the older child. The authors noticed increased tension of the frontal abdominal wall and increased load during such activity. The authors believed that women tended to activate the Valsalwa manoeuvre when lifting weights, which increases the pressure in the abdomen and may stretch and widen the linea alba. Tiredness, resulting in assuming incorrect body posture and ineffective mechanics of the body, also has unfavourable effect on DRA [12].

The study has practical value. Our data presents the scale and complexity of the diastasis recti abdominis. It is advisable that DRA specialist pay closer attention primarily to the causes of the problem (the risk factors). The study provides motivation for conducting preventive activities.

\section{Limitations of the study}

It would be advisable to continue the study, this time under close supervision of a physiotherapist. Because of the Covid-19 pandemics it was impossible to conduct the study in hospital. 


\section{Conclusions}

1. The diastasis recti abdominis muscle in postpartum women correlate with abnormal BMI and surgeries to the abdominal cavity.

2. Diastasis of the rectus abdominis muscle correlates with other dysfunctions, such as spinal pain, urinary incontinence, peristaltic disorders, sexual disorders, abdominal hernia, groin hernia, lowering of the lesser pelvis organs.

3. Further studies into DRA risk factors under close supervision of a physiotherapist are necessary.

\section{Funding}

This research received no external funding.

\section{Conflicts of interest}

The authors declare no conflict of interest.

\section{References}

1. Hills NF, Graham RB, McLean L. Comparition of trunk muscle function between women with and without diastasis recti abdominis at 1 year postpartum. Phys Ther. 2018; 98(10): 891-901.

2. Litos K. Progressive therapeutic exercise program for successful treatment of a postpartum woman with a severe diastasis recti abdominis. J Women's Health Phys Ther. 2014; 38(2): 58-73.

3. Mota P, Pascoal AG, Bo K. Normal width of the interrecti distance in pregnant and postpartum primiparous women. Musculoskelet Sci Pract. 2018; 35: 34-7.

4. Bowman K.Diastasis Recti. The whole body solution to abdominal weakness and separation. 1sted. Chichester: Lotus Publishing; 2016.

5. Coldron Y, Stokes JM, Newham JD. et al. Postpartum characteristics of rectus abdominis on ultrasound imaging. Man Ther. 2008; 13(2): 112-21.

6. Parker MA, Millar Al, Dugan S. Diastasis rectus abdominis and lumbo-pelvic pain and dysfunction - are they related? J of Women's Health Phys Ther. 2009; 33(2): 15-22.

7. Mota PG, Pascoal AG, Bo K, et al. Prevalence and risk factors of diastasis recti abdominis from late pregnancy to 6 months postpartum, and relationship with lumbo-pevic pain. Man Ther. 2015; 20(1): 200-5.

8. Veljovic F, Straus S, Karabdic I. Spinal column and abdominal muscles loading in pregnant women dependent on working posture. Acta Inform Med. 2019; 27(1): 54-7.

9. Spitzangle TM, Leong FC, Dillen LR. Prevalence of diastasis recti abdominis in urogynecological patient population. Int Urygynecol J Pelvic Floor Dysfunct. 2007; 18(3): 321-8.
10. Acharry N, Kutty RK. Abdomial exercise with bracing, a therapeutic efficacy in reducing diastasis-recti among postpartal females. Int J Physiother Res. 2015; 3(2): 999-05.

11. Jachacz-Łopata M, Milka D. Rozejście mięśnia prostego brzucha. Terapia kompleksowa. Wrocław: MedPharm; 2019.

12. Candido G, Lo T, Janssen PA. Risk factors for diastasis of the Recti Abdominis. J Assoc Chart Physiother Womens Health. 2005; 97: 49-54.

13. Sperstad JB, Tennfjord MK, Hildev G, et al. Diastasis recti abdominis during pregnancy and 12 months after childbirth: prevalence, risk factors and report of lumbopelvic pain. Braz J Sport Med. 2016; 0: 1-6.

14. Lo T, Candido G, Janssen P. Diastasis of the recti abdominis in pregnancy: risk factors and treatment. Phys Ther. 1999; 51: 32-7.

15. Thabet AA, Alshehri MA. Efficacy of deep core stability exercise program in postpartum women with diastasis recti abdominis: a randomised controlled trial. J Musculoskelet Neuronal Interact. 2019; 19(1): 62-8.

16. Reinpold W, Köckerling F, Bittner R. Classification of Rectus Diastasis - A Proposal by the German Hernia Society (DHG) and the International Endohernia Society (IEHS). Front Surg. 2019; 6(1): 1-6.

17. Olsson A, Kiwanuka O, Wilhelmsson S. Cohort study of the effect of surgical repair of symptomatic diastasis recti abdominis on abdominal trunk function and quality of life. B S J Open. 2019; 3(6): 750-8.

18. Naal FD, Hatzung G, Müller A, et al. Validation of a self-reported Beighton score to assess hypermobility in patients with femoroacetabular impingement. Inter Orthop. 2014; 38(11): 2245-50.

19. Biernat E, Stupnicki R, Gajewski AK. Miedzynarodowy Kwestionariusz Aktywności Fizycznej (IPAQ) - wersja polska. Wych Fiz Sport. 2007; 51(1): 47-54.

20. Nahabedian MY. Management strategies for diastasis recti. Semin Plast Surg. 2018; 32(3):147-54.

21. Benjamin DR, Van de Water ATM, Peiris CL. Effects of exercise on diastasis of the rectus abdominis muscle in the antenatal and postnatal periods: a systematic reviev. Phys Ther. 2013; 100(1): 1-8.

22. Bo K, Hilde G, Tennifjord M, et al. Diastasis recti abdominis and pelvic floor muscle function. A cross sectional study of priparous women during pregnancy and postpartum. Physiother. 2015; 101(1): 161-2.

23. Theodorsen NM, Strand LI, Bo K. Effect of pelvic floor and transversus abdominis muscle contraction on interrecti distance in postpartum women: a cross-section experimental study. Physiother. 2019; 05(3): 315-20.

24. Turan V, Colluoglu C, Turkyilmaz E, et al. Prevalence of diastasis recti abdominis in the population of young multiparous adults in Turkey. Ginekol Pol. 2011; 82(11): 817-21. 
25. Pascoal AG, Dionisio S, Cordeiro F. Inter-rectus distance in postpartum woman can be reduced by isometric contraction of the abdominal muscles: a preliminary case-control study. Physiother. 2014; 100(4): 344-8.

26. Michalska A, Rokita W, Wolder D, Pogorzelska J, Kaczmarczyk K. Diastasis recti abdominis-a review of treatment methods, Ginekol Pol. 2018; 98(2): 97-101.

27. Emanuelsson P, Gunnarsson U, Dahlstrand U. Operative correction of abdominal rectus diastasis (ARD) reduces pain and improves abdominal wall muscle strength: A randomized, prospective trial comparing retromuscular mesh repair to double-row, self-retaining sutures. Surg. 2016; 160(5): 1367-75.

28. Bobowik P, Dąbek A. Physiotherapy in women with diastasis of the rectus abdominis muscles. Adv Rehab. 2018; 32(3): 11-7. 